\title{
Trophic contamination by octocrylene does not affect aerobic metabolic scope in juveniles clownfish
}

\author{
Julie Lucas ${ }^{1 *}$, Valentin Logeux ${ }^{2}$, Alice MS Rodrigues ${ }^{1}$, Didier \\ Stien ${ }^{1}$ and Philippe Lebaron ${ }^{1}$ \\ 'Department of Oceanological Observatory, Biodiversity and Microbial Biotechnologies Laboratory, \\ Sorbonne University, 66650 Banyuls-sur-Mer, France \\ ${ }^{2}$ Department of Oceanological Observatory, CNRS, Research Federation, Sorbonne University, 66650 \\ Banyuls-sur-Mer, France
}

Received: 02 July, 2020
Accepted: 23 July, 2020

Published: 25 July, 2020

*Corresponding author: Dr. Julie Lucas, Department of Oceanological Observatory, Biodiversity and Microbial Biotechnologies Laboratory, Sorbonne University, 66650 Banyuls-sur-Mer, France, E-mail: lucas@obsbanyuls.fr, julie.lucas@laposte.net

Keywords: Amphiprion ocellaris; Static respirometry; Metabolic rate; Trophic exposure

https://www.peertechz.com

Check for updates

\begin{abstract}
The effect of trophic exposure to Octocrylene (OC) on aerobic metabolism of clownfish Amphiprion ocellaris was investigated. There were no significant differences in Standard Metabolic Rate (SMR), Active Metabolic Rate (AMR) or aerobic metabolic scope (AS) at the concentration of $10 \mu \mathrm{g} / \mathrm{g}$ of octocrylene in diet of juvenile's clownfish whatever the time of exposure. This suggests that under these experimental conditions, exposure to $\mathrm{OC}$ in food at a concentration of $10 \mu \mathrm{g} / \mathrm{g}$ did not influence aerobic metabolism of this species.
\end{abstract}

\section{Abbreviations}

UV: Ultra Violet; OC: Octocrylene; AS: Aerobic Metabolic Scope; AMR: Active Metabolic Rate; SMR: Standard Metabolic Rate; $\mathrm{MO}_{2:}$ Oxygen consumption

\section{Introduction}

Over the last decade, public interest in UV filters has increased because of their potential ecological risk and due to their occurrence and persistence in aquatic ecosystems [1,2]. Sixty different organic UV filters are used on the world market [3] and among them, octocrylene (OC, CAS no. 6197-30-4) is one of the most frequently used and detected in the environment. Due to his absorption of UVB and short UVA radiations, it is used in various cosmetics including sunscreens to provide protection from UV radiations [4-6]. OC is introduced into the aquatic environment indirectly from wastewater treatment plants or directly during human aquatic recreational activities $[7,8]$.

OC is found in various environmental compartments including surface water, wastewater, living organisms, and sediment. Its concentration can reach $7 \mu \mathrm{g} / \mathrm{L}$ in the water column [2,9-11]. In sediments, OC concentration can reach 400 $\mathrm{ng} / \mathrm{g}$ dw [2,12].

The widespread occurrence of OC in the environment has led to its frequent detection in biota. Due to its lipophilic properties and stability, OC tend to accumulate in aquatic organism [5,10,13-18]. The wide distribution of OC is all the more disturbing since it has recently been shown that it could be transformed and accumulated in forms that are more difficult to detect and quantify [19]. So far, little information is available on the toxic effects of OC to aquatic species. Recent studies on coral have demonstrated that OC disrupt mitochondrial metabolism, polyp retraction or decrease photosynthetic efficiency $[19,20]$. OC exposure could also impair growth of algae and sea urchin embryos [21]. On fish, OC exhibits developmental and reproductive toxicity and acts as endocrine disruptor $[14,22,23]$.

In this study we examined the response of fish exposed to OC through the assessment of aerobic metabolic scope (AS) as 
an indicator of the physiological state of the organism [24]. The AS represents the capacity of an organism to provide oxygen to sustain energy-demanding activities (locomotion, digestion and feeding) is therefore an optimal measurable fitness proxy [24]. The AS is defined as the difference between Active Metabolic Rate (AMR), which is the highest metabolic rate the organism can sustain, usually during maximal activity, and the Standard Metabolic Rate (SMR), the metabolic rate necessary to maintain vital functions and measured under resting conditions at a known ambient temperature [24-26]. AS is known to be modulated by pollutants [29-33]. The main hypotheses were that chronic exposure to OC may affect AS by (i) activating costly repair and detoxification pathways thus increasing SMR [34], (ii) impairing organs or mechanism involved in oxygen transport which would decrease AMR. Clown fish (Amphiprion ocellaris, Cuvier 1930) was chosen as marine biological model and coral reef species of interest.

\section{Material and methods}

\section{Clownfish maintenance conditions}

Clownfish (Amphiprion ocellaris) were obtained from several breeding pairs housed in our laboratory. After 15 days of larval development (green seawater method), juveniles were reared in the same $60 \mathrm{~L}$ tank in our supply rearing facility, in artificial sea water (RedSeaSalt) at a salinity of $34 \%$. Water was kept at $28{ }^{\circ} \mathrm{C}$ with a 12:12-hour light: Dark photoperiod. Ammonia, nitrites, and nitrates were monitored weekly and remained within recommended ranges. Juveniles were fed twice a day (i) in the morning with fresh chopped food mix composed of mussels, shrimp, squid, nori algae and vitamins, (ii) in the afternoon with Artemia sp. nauplii.

At the age of 5 months, two groups of 20 fishes were transferred for two months in two 60L tanks (closed-system aquariums filled with artificial sea water maintained at $28^{\circ} \mathrm{C}$ ).

\section{Food contamination protocol and fish exposure}

Artificial dry food was spiked with OCat a target concentration of $10 \mathrm{\mu g} / \mathrm{g} \mathrm{dw}$ of food based on environmental concentrations find in literature. A control treatment was also included and consisted of feeding a group of fishes with uncontaminated food, only impregnated by the solvent dichloromethane. This solvent was used to improve UV incorporation into the food, and then removed by evaporation. Trophic contamination was conducted during 2 months by feeding juvenile clownfishes twice a day. The ration of food was $2 \%$ of the biomass in each tank in order to maintain constant growth.

\section{Aerobic metabolic scope}

Experimental set-up: To assess the fish aerobic metabolic rate, six identical circular size-adapted respirometers (diameter: $3.75 \mathrm{~cm}$, volume: $0.061 \mathrm{~L}$ ) were employed. These were immersed in two buffer tanks (depth $\times$ length $\times$ height: $25 \times 80 \times 40 \mathrm{~cm}$ ) filled with temperature-controlled and aerated water. Oxygen consumption was measured by intermittentflow respirometry [35], where the water supply in each respirometer was provided by flush pumps controlled by a timer. This system alternated phases of flushing and oxygen renewal with phases of measurement of oxygen consumption $\left(\mathrm{MO}_{2}\right)$, each of which lasted $30 \mathrm{~min}$. Finally, a multichannel peristaltic pump was installed to create continuous water flow and ensure water mixing inside each of the chambers. Each respirometer was equipped with an optic fiber sensor (PreSens; Germany, www.presens.com) connected to an analyzer (Witrox 4, PreSens) to record dissolved oxygen levels. Optic fibers were calibrated at 0 and $100 \%$ air saturation at a temperature of 28 ${ }^{\circ} \mathrm{C}$. A factor of conversion based on oxygen solubility into water was used to convert oxygen data from percentage saturation to $\mathrm{mgO}_{2} \cdot \mathrm{L}^{-1}$ (100\% was equivalent to $6.48 \mathrm{mgO} \cdot \mathrm{L}^{-1}$ for a temperature of $28{ }^{\circ} \mathrm{C}$ and a salinity of $34 \%$ ). Oxygen level was recorded every $5 \mathrm{~s}$ with the program Witroxview (PreSens).

Experimental protocol: Respirometry experiments occurred at one month and two months of exposure. Before each experiment, fishes were starved for $24 \mathrm{~h}$. For each trial, six fishes (three per treatment) were tested individually. One fish was place in one respirometer and the test was composed of two consecutive phases. First, to increase fish metabolism and assess AMR, each fish was transferred and chased with a stick in a $1 \mathrm{~L}$ tank [36-39]. When the fish was exhausted, it was transferred into a respirometer. The oxygen consumption of the fish was immediately recorded for $30 \mathrm{~min}$ to calculate AMR. For each fish, this process was repeated a second time during 30 min to confirm the accuracy of the AMR assessment. The second step consisted of a resting period of $48 \mathrm{~h}$ to reach and estimate SMR. During this period, fish were let undisturbed and $\mathrm{MO}_{2}$ was regularly and automatically measured (30 $\mathrm{MO}_{2}$ measurement:30 min water renewal). Before and after each trial, a blank measurement was performed to quantify microbial oxygen consumption in the respirometer. A linear change in background $\mathrm{MO}_{2}$ over the $48 \mathrm{~h}$ experimental trial was assumed and subtracted the expected value from the corresponding total $\mathrm{MO}_{2}$ measured. From these oxygen measurements, SMR was estimated according to the method described by Steffensen, et al. [40] and Chabot, et al. [41]. Briefly, SMR were calculated from frequency distribution of $\mathrm{MO}_{2}$ recorded during the last $24 \mathrm{~h}$ of the test. This generally produces a bimodal frequency distribution due to the routine activity of the fish. Two normal curves were fit to the frequency histogram to separate the lower SMR distribution of $\mathrm{MO}_{2}$ from the higher $\mathrm{MO}_{2}$ values owing to spontaneous activity. The mean of the lower distribution was considered to be the SMR for that individual. During all the experiments, oxygen concentration was never lower than $75 \%$ oxygen saturation in each respirometer. After the $48 \mathrm{~h}$, the fish was removed from the respirometer and euthanized using MS222 (400 mg.L $\mathrm{L}^{-1}$, Sigma-Aldrich). The body mass (Mmeas) of each individual was measured and fish were dissected in order to sample liver and white muscle for OC and OC metabolites analyses.

\section{Calculations}

Oxygen consumption $\mathrm{MO}_{2}$ is expressed in $\mathrm{mg} \mathrm{O}_{2} \cdot \mathrm{g}^{-1} \cdot \mathrm{h}^{-1}$ and calculated using the following formula:

$\mathrm{MO}_{2 \text { meas }}=\Delta\left[\mathrm{O}_{2}\right] \cdot \Delta \mathrm{t}^{-1} \cdot \mathrm{V} \cdot \mathrm{M}_{\text {meas }}{ }^{-1} \quad$ Equation (1) 
where $\Delta\left[\mathrm{O}_{2}\right]$ (in $\mathrm{mgO}_{2} \cdot \mathrm{L}^{-1}$ ) is the variation in oxygen concentration during the measurement period $\Delta \mathrm{t}$ (in $\mathrm{h}$ ), $\mathrm{V}$ (in $\mathrm{L}$ ) is the volume of the respirometer minus the volume of the fish and $M_{\text {meas }}$ (in $g$ ) is the mass of the fish.

An allometric relationship exists between oxygen consumption and body mass, which encourages correction of $\mathrm{MO}_{2 \text { meas }}$ using the following formula:

(2)

$\mathrm{MO}_{\text {2cor }}=\mathrm{MO}_{\text {2meas }} \cdot\left(\mathrm{M}_{\text {meas }} \cdot \mathrm{M}_{\text {cor }}^{-1}\right)^{1-\mathrm{b}}$

Equation

where $\mathrm{MO}_{2 \text { cor }}$ (in $\mathrm{mgO}_{2} \cdot \mathrm{g}^{-1} \cdot \mathrm{h}^{-1}$ ) is the oxygen consumption related to a standard fish of $1 \mathrm{~g}\left(\mathrm{M}_{\text {cor }}\right), \mathrm{MO}_{\text {2meas }}$ (in $\left.\mathrm{mgO}_{2} \cdot \mathrm{g}^{-1} \cdot \mathrm{h}^{-1}\right)$ is the oxygen consumption estimated with eq. 1 for experimental fish the mass of which was $M_{\text {meas }}$ (in $g$ ) and $b$ is the allometric scaling exponent describing the relationship between oxygen consumption and the mass of fish.

\section{Statistical analysis}

The statistical analysis was carried out using GraphPad Prism software. For all analyses, the normality and homoscedasticity were checked through the Shapiro and Barlett tests, respectively. These conditions, necessary to apply parametric tests, were respected. ANOVA was therefore used to determine significant differences due to the treatment and the time of exposure. If necessary, a Tukey post hoc test was applied to determine which treatments differed significantly from the control. The differences were considered significant when $\mathrm{p}<0.05$

\section{Fish tissue extraction and HPLC analyses}

The fish muscle or liver were weighted and placed into a 2 $\mathrm{mL}$ Eppendorff tube containing microbeads. Dichloromethane $(0.5 \mathrm{~mL}$ ) was added and the tube was homogenous for $4 \mathrm{~min}$ in FastPrep homogenizer instrument (MP Biomedicals ${ }^{\mathrm{TM}}$ ). The tubes were centrifuged and the supernatant transferred into a HPLC vial for analysis. The UHPLC-MS ${ }^{2}$ analysis was performed as described before in our group $[19,42]$. OC was not detected in the analyses (no significant difference between treated and untreated fishes). This was confirmed by comparison of the pic area from extracted ion chromatogram $(\mathrm{m} / \mathrm{z}$ 362.2115) with the one of a commercial standard of OC at different concentrations (from 0.5 to $2.5 \mu \mathrm{g} / \mathrm{mL}$ ). OC analogs were searched for in the $\mathrm{MS}^{2}$ spectra by extracting the ion at $\mathrm{m} / \mathrm{z} 232.0757$ corresponding to the (2-cyano-3,3-diphenylallylidyneoxonium) common to the fragmentation spectra of all OC-fatty acid conjugates. Whenever the ion was detected, the parent ion molecular formula and its $\mathrm{MS}^{2}$ spectrum were analyzed manually as described in Stien, et al. [19].

\section{Results and discussion}

Our study investigated for the first time the toxicity of OC on aerobic scope of fish after dietary exposure. Only few studies have tested the effect of OC on fish development and reproduction $[14,22,23]$.

No significant differences in AMR ( $p>0.05$; Figure 1a), SMR ( $p>0.05$; Figure $1 b)$ and AS ( $p>0.05$; Figure 1c) were observed among treatments (Control and OC) after one and two months of exposure. Under these experimental conditions and at the life stage tested, trophic exposure to OC did not affect aerobic scope of this species. These results suggest that $A$. ocellaris would not have a reduced capacity to sustain oxygendemanding activities such as locomotion, digestion or growth [28]. This is contrary to our initial hypothesis which stated that OC may impact both SMR and AMR. Comparison with other studies is still limited since no data on aerobic metabolism of clownfish are available and only few studies have investigated the effect of UV filters on fish.

The present results suggest that the level of contamination tested was not sufficiently extreme to induce significant variation in aerobic metabolism in our experimental conditions. OC exposure did not induce supplementary costs of maintenance due to detoxification processes in clownfish which is contrary to the initial hypotheses. The way of exposure also may not induce impairments in the mechanisms involved in metabolic regulation. It is also worth noting that organisms that suffer long-term chronic environmental stress can present physiological adaptations to maintain their aerobic metabolism and their homeostasis [43]. Chronic exposure to OC may have induced such adaptations in A. ocellaris.
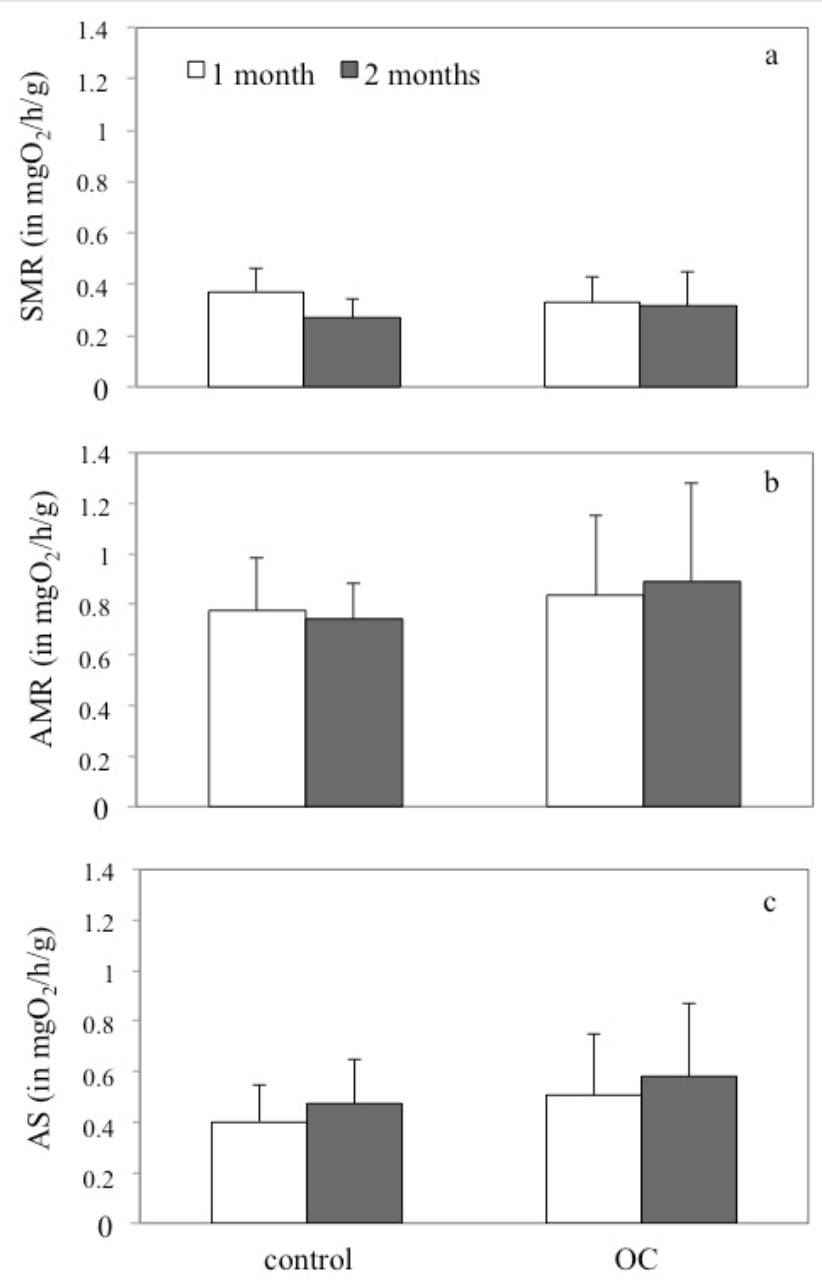

Figure 1: (a) Standard metabolic rate (SMR), (b) active metabolic rate (AMR) and (c) aerobic metabolic scope (AS) in juvenile clown fishes exposed to control or OC treatment. Values are means \pm S.D.

Citation: Lucas J, Logeux V, Rodrigues AM, Stien D, Lebaron P (2020) Trophic contamination by octocrylene does not affect aerobic metabolic scope in juveniles clownfish. Ann Environ Sci Toxicol 4(1): 050-054. DOI: https://dx.doi.org/10.17352/aest.000026 
Others studies on OC did not show any significant effect in environmentally relevant concentrations on zebrafish or other aquatic organisms $[14,44,45]$. Li, et al. [44] have tested the effect of dietary exposure to OC and mixtures of UV filters. They did not observed lethal effects on adults zebrafish fed by OC or mixture containing OC during 25 or 47 days. They observed impairment on embryo of the next. It may be interesting to study maternal transfer and trans-generation effect of UV filters.

Juvenile clown fish had 5 months during the experiments. At this age, fishes were completely developed. Further experiments on trophic exposure from larval stage could be interesting in order to detect any putative impairment on development which could later impair oxygen transport and thus aerobic metabolism.

It could be interesting to perform further experiments using a dose-response study in order to evaluate the response of the fish to higher amounts of OC intake. Due to its relative lipophilicity, OC tends to accumulate in aquatic life. For example, OC was detected in the muscle of brown trout [13], in dolphin [15], in liver of cod [5]. In the present study, OC and its metabolites were not found in clownfish white muscle and liver samples. This may be explained by the fish capacity to metabolize UV filters in more water-soluble components easier to excrete. A similar process has been described for humans $[44,45]$. Further investigations are still needed with OC and other UV filters using a range of different concentrations to mimic different environmental conditions, and also using different way of exposure.

\section{Conclusion}

OC did not impair aerobic scope of clownfish after dietary exposure. This work is the first report on the impact of $\mathrm{OC}$ on aerobic metabolism of fish. Despite the numerous studies on fish metabolism, it is difficult to establish a clear conclusion regarding the effect of persistent organic pollutant on fish physiology. Studies differ by the concentrations tested, the way of exposure or the organic pollutant tested. In view of the intense use of personal care products containing $\mathrm{OC}$, there is an important need of ecotoxicological studies to evaluate the impact of this chemical to marine organisms.

\section{Acknowledgements}

All experiments were carried out at USR 3579 SU-CNRS Laboratoire de Biodiversité et Biotechnologies Microbiennes (LBBM), Observatoire de Banyuls sur mer, Banyuls sur mer, France. We thank BIO2MAR and BIOPIC platforms for providing technical support and access to instrumentation as well as the shared aquaria service of Oceanological Observatory of Banyulssur-Mer. We also thank LIENSs laboratory and especially Dr. Christel Lefrancois for generously lending us some of the respirometry equipment. This study was conducted under the agreement of the Animal Care Committee $N^{\circ}$ A66-01-601.

\section{References}

1. Tovar-Sanchez A, Sanchez-Quiles D, Basterretxea G, Benede JL, Chisvert A, et al. (2013) Sunscreen products as emerging pollutants to coastal waters. PLoS One 8: e65451. Link: https://bit.ly/3eS543S
2. Tsui MMP, Leung HW, Wai TC, Yamashita N, Taniyasu S, et al. (2014) Occurrence, distribution and ecological risk assessment of multiple classes of UV filters in surface waters from different countries. Water Res 67: 55-65. Link: https://bit.ly/32KHG67

3. Shaath NA (2010) Ultraviolet filters. Photochemical and Photobiological Sciences 9: 464-469. Link: https://rsc.li/39kheBu

4. Manova E (2014) Consumer exposure to ultraviolet (UV) filters in personal care products. Thesis. Link: https://bit.ly/3jARfLO

5. Langford KH, Reid MJ, Fjeld E, Øxnevad S, Thomas KV (2015) Environmental occurrence and risk of organic UV filters and stabilizers in multiple matrices in Norway. Environ Int 80: 1-7. Link: https://bit.ly/3jxm6YI

6. Sunyer A, González-Navarro A, Serra-Roig MP, Serrano N, Díaz-Cruz M, et al. (2019) First application of carbon-based screen-printed electrodes for the voltammetric determination of the organic UV filters oxybenzone and octocrylene. Talanta 196: 381-388. Link: https://bit.ly/3eTeDQ3

7. Giokas DL, Sakkas VA, Albanis TA, Lampropoulou DA (2005) Determination of UV-filter residues in bathing waters by liquid chromatography UV-diode array and gas chromatography-mass spectrometry after micelle mediated extraction-solvent back extraction. J Chromatogr A 1077: 19-27. Link: https://bit.ly/3fUOF1Q

8. Ramos S, Homem V, Alves A, Santos L (2016) A review of organic UVfilters in wastewater treatment plants. Environ Int 86: 24-44. Link: https://bit.ly/2Cy1nn4

9. Langford $\mathrm{KH}$, Thomas KV (2008) Inputs of chemicals from recreational activities into the Norwegian coastal zone. J Environ Monit 10: 894-898. Link: https://rsc.li/2OQCjKt

10. Molins-Delgado D, Máñez M, Andreu A, Hiraldo F, Eljarrat E, et al. (2017) A potential new threat to wild life: presence of UV filters in bird eggs from a preserved area. Environ Sci Technol 51: 10983-10990. Link: https://bit.ly/3g66qtv

11. Cabrera-Peralta J, Pena-Alvarez A (2018) Simple method for the determination of personal care product ingredients in lettuce by ultrasound-assisted extraction combined with solid-phase microextraction followed by GC-MS. J Sep Sci 41: 2253-2260. Link: https://bit.ly/2CVD1DA

12. Kameda $Y$, Kimura K, Miyazaki M (2011) Occurrence and profiles of organic sun-blocking agents in surface waters and sediments in Japanese rivers and lakes. Environ Pollut 159: 1570-1576. Link: https://bit.ly/2ZTjtsc

13. Buser HR, Balmer ME, Schmid P, Kohler M (2006) Occurrence of UV Filters 4-Methylbenzylidene Camphor and Octocrylene in Fish from Various Swiss Rivers with Inputs from Wastewater Treatment Plants. Environ Sci Technol 40 1427-1431. Link: https://bit.ly/2CE1HAA

14. Blüthgen N, Meili N, Chew G, Odermatt A, Fent K (2014) Accumulation and effects of the UV-filter octocrylene in adult and embryonic zebrafish (Danio rerio). Sci Total Environ 476-477: 207-217. Link: https://bit.ly/2CEuh4S

15. Gago-Ferrero P, Díaz-Cruz MS, Barceló D (2015) UV filters bioaccumulation in fish from Iberian river basins. Sci Total Environ 518-519: 518-525. Link: https://bit.ly/3jyNAgH

16. Pawlowski S, Lanzinger AC, Dolich T, FüßI S, Salinas ER, et al. (2019) Evaluation of the bioaccumulation of octocrylene after dietary and aqueous exposure. Sci Total Environ 672: 669-679. Link: https://bit.ly/32LTUeP

17. Peng X, Zhu Z, Xiong S, Fan Y, Chen G, et al. (2020) Tissue Distribution, Growth Dilution, and Species-Specific Bioaccumulation of Organic Ultraviolet Absorbents in Wildlife Freshwater Fish in the Pearl River Catchment, China. Environ Toxicol Chem 39: 343-351. Link: https://bit.ly/2ZPIzbF

18. Saunders LJ, Hoffman AD, Nichols JW, Gobas FA (2020) Dietary Bioaccumulation and Biotransformation of Hydrophobic Organic Sunscreen Agents in Rainbow Trout. Environ Toxicol Chem 39: 574-586. Link: https://bit.ly/2E5aFak

Citation: Lucas J, Logeux V, Rodrigues AM, Stien D, Lebaron P (2020) Trophic contamination by octocrylene does not affect aerobic metabolic scope in juveniles clownfish. Ann Environ Sci Toxicol 4(1): 050-054. DOI: https://dx.doi.org/10.17352/aest.000026 
19. Stien D, Clergeaud F, Rodrigues AMS, Lebaron K, Pillot R, et al. (2019) Metabolomics Reveal That Octocrylene Accumulates in Pocillopora Damicornis Tissues as Fatty Acid Conjugates and Triggers Coral Cell Mitochondrial Dysfunction. Anal Chem 91: 990-995. Link: https://bit.ly/32LTh4X

20. He T, Tsui MMP, Tan CJ, Ma CY, Yiu SKF, et al. (2019) Toxicological effects of two organic ultraviolet filters and a related commercial sunscreen product in adult corals. Environ Pollut 245: 462-471. Link: https://bit.ly/3fTMxFO

21. Giraldo A, Montes R, Rodil R, et al. (2017) Ecotoxicological Evaluation of the UV Filters Ethylhexyl Dimethyl p-Aminobenzoic Acid and Octocrylene Using Marine Organisms Isochrysis galbana, Mytilus galloprovincialis and Paracentrotus lividus. Arch Environ Contam Toxicol 72: 606-611. Link: https://bit.ly/2D0yaAK

22. Yan S, Liang M, Chen R, Hong X, Zha J (2020) Reproductive toxicity and estrogen activity in Japanese medaka (Oryzias latipes) exposed to environmentally relevant concentrations of octocrylene. Environ Pollut 261 114104. Link: https://bit.ly/2CXY9ZS

23. Zhang QY, Ma XY, Wang XC, Ngo HH (2016) Assessment of multiple hormone activities of a UV-filter (octocrylene) in zebrafish (Danio rerio). Chemosphere 159: $433-441$

24. Fry FEJ (1947) The effects of the environment on animal activity. University of Toronto studies. Biology Series 55: 1-62. Link: https://bit.ly/3eQV7nl

25. Brett JR (1964) The respiratory metabolism and swimming performance of young sockeye salmon. Can J Fish Aquat Sci. 5: 1183-1226. Link: https://bit.ly/3fUorum

26. White CR, Phillips NF, Seymour RS (2005) The scaling and temperature dependence of vertebrate metabolism. Biology letters 2. Link: https://bit.ly/2EbWDE1

27. Fry FEJ (1971) The effect of environmental factors on the physiology of fish Fish Physiology (Hoar, W.S., Randall, D.J., eds.), CA: Academic Press, New York 6: 1-98. Link: https://bit.ly/2ZSfMTZ

28. Claireaux G, Lefrançois C (2007) Linking environmental variability and fish performance: integration through the concept of scope for activity. Philos Trans A Math Phys Eng Sci 362: 2031-2041. Link: https://bit.ly/2ZREJ1B

29. Davoodi F, Claireaux G (2007) Effects of exposure to petroleum hydrocarbons upon the metabolism of the common sole Solea solea. Marine Pollution Bulletin 54: 928-934. Link: https://bit.ly/20NVjsX

30. Johansen JL, Jones GP (2011) Increasing ocean temperature reduces the metabolic performance and swimming ability of coral reef damselfishes. Glob Chang Biol 17: 2971-2979. Link: https://bit.ly/3jwfCZY

31. Mager EM, Grosell M (2014) Effects of acute and chronic waterborne lead exposure on the swimming performance and aerobic scope of fathead minnows (Pimephales promelas). Comp Biochem Physiol C Toxicol Pharmacol 54: 7-13.

32. Campbell C, Rudensky A (2020) Roles of Regulatory T Cells in Tissue Pathophysiology and Metabolism. Cell Metabolism 31: 8-25. Link: https://bit.ly/2WLPXD5
33. Kulesza A, Leonardi EM, McClelland GB (2020) Influence of 96h sub-letha copper exposure on aerobic scope and recovery from exhaustive exercise in killifish (Fundulus heteroclitus). Aquatic Toxicology 218: 105373. Link: https://bit.ly/2WK2Tcj

34. Calow P (1991) Physiological costs of combating chemical toxicants: ecological implications. Comparative Biochemistry and physiology. C, Comparative Pharmacology and Toxicology 100: 3-6. Link: https://bit.ly/3eTvp1m

35. Steffensen JF (1989) Some errors in respirometry of aquatic breathers: how to avoid and correct for them. Fish Physiol Biochem 6: 49-59. Link: https://bit.ly/30wVhuQ

36. Roche D, Binning SA, Bosiger Y, Johansen JL, Rummer JL (2013) Finding the best estimates of metabolic rates in a coral reef fish. J Exp Biol 216: 2103 2110. Link: https://bit.ly/2WLmFEq

37. Norin T, Malte $\mathrm{H}$, Clark TD (2014) Aerobic scope does not predict the performance of a tropical eurythermal fish at elevated temperatures. J Exp Biol 217: 244-251. Link: https://bit.ly/20NojkL

38. Norin T, Clark TD (2016) Aerobic scope does not predict the performance of a tropical eurythermal fish at elevated temperatures. J Fish Biol 88: 122-151.

39. Lucas J, Bonnieux A, Lyphout L, Cousin X, Miramand P, et al. (2016) Trophic contamination by pyrolytic polycyclic aromatic hydrocarbons does not affect aerobic metabolic scope in zebrafish Danio rerio. J Fish Biol 88: 433-442. Link: https://bit.ly/30BdgjW

40. Steffensen JF, Bushnell PG, Schurmann H (1994) Oxygen consumption in fou species of teleosts from Greenland: no evidence of metabolic cold adaptation. Polar Biol 14: 49-54. Link: https://bit.ly/2BmoOio

41. Chabot D, Steffensen JF, Farrell AP (2016) The determination of standard metabolic rate in fishes. J Fish Biol 88: 81-121. doi:10.1111/jfb.12845 Link:

42. Stien D, Suzuki M, Rodrigues AMS, Yvin M, Clergeaud F, et al. (2020) A Unique Approach to Monitor Stress in Coral Exposed to Emerging Pollutants. Scientific Reports 10: 9601. Link: https://bit.ly/30CNIZg

43. Barton BA (2002) Stress in Fishes: A Diversity of Responses with Particular Reference to Changes in Circulating Corticosteroids. Integrative and Comparative Biology 42: 517-525. Link: https://bit.ly/2ZRQIlh

44. Li AJ, Law JCF, Chow CH, Huang Y, Li K, et al. (2018) Joint Effects of Multiple UV Filters on Zebrafish Embryo Development. Environmental Science Technology 52: 9460-9467. Link: https://bit.ly/39nEoXu

45. Kaiser D, Sieratowicz A, Zielke H, Oetken M, Hollert $H$, et al. (2012) Ecotoxicological effect characterisation of widely used organic UV filters. Environ Pollut 163: 84-90. Link: https://bit.ly/3jx0P1d

46. Bury D, Belov VN, Qi Y, Hayen H, Volmer DA, et al. (2018) Determination of Urinary Metabolites of the Emerging UV Filter Octocrylene by Online-SPE-LC MS/MS. Anal Chem 90: 944-951. Link: https://bit.ly/30B1S7S

47. Bury D, Modick-Biermann H, Leibold E, Brüning T, Koch HM (2019) Urinary metabolites of the UV filter octocrylene in humans as biomarkers of exposure. Archives Toxicology 93: 1227-1238. Link: https://bit.ly/3hEUQ95

Copyright: @ 2020 Lucas J, et al. This is an open-access article distributed under the terms of the Creative Commons Attribution License, which permits unrestricted use, distribution, and reproduction in any medium, provided the original author and source are credited.

Citation: Lucas J, Logeux V, Rodrigues AM, Stien D, Lebaron P (2020) Trophic contamination by octocrylene does not affect aerobic metabolic scope in juveniles clownfish. Ann Environ Sci Toxicol 4(1): 050-054. DOI: https://dx.doi.org/10.17352/aest.000026 